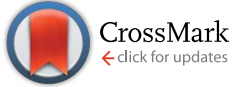

Cite this: RSC Adv., 2017, 7, 957

Received 3rd October 2016 Accepted 16th November 2016

DOI: $10.1039 / c 6 r a 24696 f$

www.rsc.org/advances

\title{
Solar mediated reduction of graphene oxide $\uparrow$
}

\author{
Manonmani Mohandoss, ${ }^{\text {ab }}$ Soujit Sen Gupta, ${ }^{c}$ Anith Nelleri, ${ }^{b}$ T. Pradeep ${ }^{c}$ \\ and Shihabudheen M. Maliyekkal ${ }^{\star a}$
}

This paper explores the reduction of water dispersed graphene oxide (GO) by sunlight as an environmentally friendly alternative to conventional methods of reduction of GO. The possible mechanism of the reduction process is delineated. The electrical and thermal conductivity, the degree of reduction and structural defects of sunlight reduced GO (sRGO) are studied thoroughly and compared with RGO samples produced through hydrazine (hRGO) and hydrothermal (hyRGO) reduction routes. The study reveals that the production of SRGO is feasible and its electronic properties are on a par with those of hRGO. Interestingly, SRGO showed the least structural defects, good dispersibility and higher conductivity vis-avis its counterparts. This cost effective and environmentally friendly method of reducing GO to RGO with enhanced electronic properties may find applications in bio-sensing and electrochemical energy storage devices.

\section{Introduction}

Graphene, one atom thick 2D sheets of $\mathrm{sp}^{2}$ hybridised carbon atoms arranged in a honeycomb lattice, ${ }^{1}$ has attracted overwhelming academic and industrial research interest due to its excellent mechanical, electrical, thermal and optical properties with promising applications. ${ }^{2}$ Diverse methods of graphene synthesis have been developed over the years expecting distinct physical and chemical properties. ${ }^{3}$ The journey started with the successful separation of graphene by scotch tape based microcleaving of highly oriented pyrolytic graphite (HOPG). ${ }^{4}$ The low yield and difficulty in tearing of graphene from the substrate restricted its use in laboratory scale applications for making proof-of-concept devices. This method of mechanical exfoliation may also inhibit the quality of graphene due to the possible attachment of adhesive to the graphene surface. ${ }^{5}$ Epitaxial growth on silicon carbide or metal surfaces ${ }^{6}$ and chemical vapours deposition (CVD) technique ${ }^{7}$ have emerged as alternatives to the exfoliation strategies to produce better quality graphene, especially when expecting the coverage of large substrate areas with graphene. ${ }^{8}$ Though the epitaxial method delivers high quality graphene, the stringent growth conditions and the use of costly single crystal substrates make it economically unviable for large-scale production. ${ }^{9}$ Despite the

${ }^{a}$ Environmental Engineering Division, School of Mechanical and Building Sciences, VIT University, Chennai Campus, Chennai - 600 127, India. E-mail: shihabudheen.m@vit. ac.in; sm.maliyekkal@gmail.com; Fax: +91-44-3993-2555; Tel: +91-44-3993-1266

${ }^{b}$ School of Electronics Engineering, VIT University, Chennai Campus, Chennai - 600 127, India

${ }^{c}$ DST Unit on Nanoscience and Thematic Unit of Excellence (TUE), Department of Chemistry, Indian Institute of Technology Madras, Chennai 600 036, India

$\dagger$ Electronic supplementary information (ESI) available. See DOI: $10.1039 / \mathrm{c} 6 \mathrm{ra} 24696 \mathrm{f}$ fact that the recent advancement in CVD techniques allows synthesis of graphene monolayers with large surface area, the low yield of production limits its large-scale deployment and the method is typically restricted for the precise fabrication of devices..$^{10}$ Chemical conversion of graphite to graphene is attractive over other methods due to its high reduction efficiency, good dispersibility and non-requirement of sophisticated experimental conditions. ${ }^{11}$ The wet chemical exfoliation of graphite seems to be promising for the bulk production of graphene. ${ }^{12,13}$ The method typically consists of weakening of the graphite interlayer van der Waals force and disrupting it by chemical intercalation, ${ }^{14}$ thermal expansion, ${ }^{15}$ oxidationreduction ${ }^{16}$ or by the use of surfactants. ${ }^{17}$ Hummer's method ${ }^{18}$ of chemical exfoliation is a well-established and widely practiced wet chemical technique for the bulk synthesis of water dispersible graphene oxide (GO). The process involves oxidation of graphite to GO, where large fraction of $\mathrm{sp}^{2}$ carbon atoms is converted to $\mathrm{sp}^{3}$ configurations. $\mathrm{GO}$ is then transformed to reduced graphene oxide (RGO) by reduction methods including chemical, ${ }^{19}$ hydrothermal, ${ }^{20}$ thermal, ${ }^{21}$ photo ${ }^{22,23}$ or combinations thereof. ${ }^{24}$ However, the need for the critical treatment conditions, use of hazardous and toxic reducing agents (e.g. hydrazine hydrate, ${ }^{25}$ hydroquinone ${ }^{26}$ ) and energy intensive synthesis procedures need further attention to make the production process more sustainable. Besides, the extent of removal of oxygen functionalities on GO may vary with different reduction processes. This can results in RGO with different chemical, physical and electronic properties. ${ }^{27}$ Hence, understanding the influence of reduction techniques on the properties of RGO is also important to decide its suitability for a specific application.

In this paper, we demonstrate a simple and green technique for the reduction of GO to RGO as a sustainable alternative to 
conventional reduction techniques. The proposed method uses sunlight as the sole medium for the reduction of GO to RGO. The samples were characterized thoroughly by spectroscopic and microscopic techniques. The possible mechanism of reduction of GO to RGO is proposed. The electrical conductivity, dispersibility, degree of reduction, defect repair, and thermal conductivity of sRGO were compared systematically with RGO samples synthesised through other popular reduction techniques, which includes hydrothermal and hydrazine reduction. The sunlight mediated reduction strategy seems to be viable and can produce RGO with good electrical conductivity and less structural defects.

\section{Materials and methods}

Natural graphite powder $\left(100 \mu \mathrm{m} ; 12.01 \mathrm{~g} \mathrm{~mol}^{-1}\right)$ was obtained from S.D. Fine Chem. Pvt. Ltd., India. Sulphuric acid $\left(\mathrm{H}_{2} \mathrm{SO}_{4}\right.$, 95-98\%), potassium permanganate $\left(\mathrm{KMnO}_{4}, 98.5 \%\right)$, potassium peroxy disulphate $\left(\mathrm{K}_{2} \mathrm{~S}_{2} \mathrm{O}_{8}, 98 \%\right)$, phosphorus pentoxide $\left(\mathrm{P}_{2} \mathrm{O}_{5}\right.$, $95 \%)$, hydrogen peroxide $\left(\mathrm{H}_{2} \mathrm{O}_{2}, 98 \%\right)$, were procured from Sisco Research Lab Chem. Pvt. Ltd., India. The dialysis tubing cellulose membrane with average diameter of $6 \mathrm{~mm}$ was purchased from Sigma Aldrich. All the chemicals were of analytical grade and used as received without any further purification. Unless otherwise mentioned, solutions and suspensions used in the study were prepared using deionized water (DW) of conductivity $0.056 \mu \sigma \mathrm{cm}^{-1}$.

\section{Preparation of reduced graphene oxide (RGO)}

GO was synthesized by modified Hummers method. ${ }^{28}$ This method involves the oxidation of graphite powder by sulphuric acid and potassium permanganate to produce graphite oxide and exfoliation of graphite oxide to GO. A detailed procedure is given in S1.1 of the ESI. $\dagger$ The purified dispersion of GO was stored in brown bottles (covered with aluminium foil) to cut the entry of light. The reduction of GO was carried out by exposing $0.01 \%$ dispersion of GO to sunlight for a duration of $\sim 16 \mathrm{~h}$. The temperature of GO dispersion was measured and found to be around $\sim 42 \pm 2{ }^{\circ} \mathrm{C}$. Initial $\mathrm{pH}$ of the dispersion was measured to be $4.0 \pm 0.3$ and no significant change in $\mathrm{pH}$ was observed after the reduction process. In-order to prevent possible evaporation loss and associated change in the concentration of dispersion of GO during irradiation, the reactor was completely sealed. For kinetic studies, a series of sealed bottles containing dispersion of GO were irradiated. At periodic time intervals, a pre-designated sample bottle was withdrawn and analysed using UV-Vis and Raman spectroscopy. The incident solar light intensity at the surface of irradiance during irradiation period (from 11 a.m to 4 p.m) was measured to be in the range of $42 \mathrm{~W}$ $\mathrm{m}^{-2}$ to $373 \mathrm{~W} \mathrm{~m}^{-2}$. The experiment was also performed using photovoltaic solar simulator (Ecosense Insight Solar PV simulator) with halogen lamps (350-2500 $\mathrm{nm}$ ) as the artificial source of solar radiation. The intensity of radiation from halogen lamp was adjusted similar to the natural sunlight throughout the experiment. No significant change in the rate of reduction of GO was observed under natural and simulated conditions. For comparison purpose, RGO samples were also synthesised using hydrazine (hRGO) and hydrothermal (hyRGO) heat as the reducing agents (see S1.3, S1.2 of ESI $\dagger$ for detailed procedure). The samples were later dialyzed against DW to remove ionic impurities.

\section{Instrumentation}

Thermo-fisher Scientific (EVO $300 \mathrm{PC}$ ) UV/Vis spectrophotometer was used to measure UV/Vis spectra of GO and RGO samples. XPS measurements were done with Omicron ESCA Probe spectrometer with un-monochromatized $\mathrm{Mg} \mathrm{K} \alpha$ X-rays $(h \nu=1253.6 \mathrm{eV})$. Processing of XPS spectra was done using Casa XPS software. Calibration was carried by alignment of the spectra with reference to the $\mathrm{C} 1 \mathrm{~s}$ line at $284.5 \pm 0.2 \mathrm{eV}$ associated with graphitic carbon. The confocal Raman Microscope, CRM a300 S (WITec GmbH) coupled with AFM was used for collecting Raman spectra and AFM images. The samples were also imaged using a high-resolution transmission electron microscope (HRTEM) with a UHR pole piece equipped with an EDAX (JEOL 3011, $300 \mathrm{kV}$ ). The attenuated total reflectance infrared spectroscopic (ATR-IR) measurement was performed using Thermo Scientific NICOLET iS10 FT-IR Spectrometer. Indosaw four-probe set-up (SN168) was used to measure the surface resistance for the calculation of electrical conductivity. The Horibo Jobin Yvon Uvisel spectroscopic ellipsometer was used to measure the thickness of RGO sheets. Tenmars-TM207 solar power meter was used to measure the intensity of solar radiation. Dynamic light scattering Zetasizer (Horiba SZ100) was used to study the dispersibility of RGO samples by measuring their zeta potential.

\section{Results and discussion}

The as-produced RGO samples were characterised in detail with various spectroscopic and microscopic techniques. Fig. 1A shows UV/Vis spectrum of GO sample synthesized through modified Hummer's method (red trace). The data show a prominent absorbance peak of GO centred at $239 \mathrm{~nm}$ and a shoulder peak at $302 \mathrm{~nm}$, which can be ascribed to $\pi-\pi^{*}$ transition of $\mathrm{C}-\mathrm{C}$ bonds and $\mathrm{n}-\pi^{*}$ transition of $\mathrm{C}=\mathrm{O}$ bonds, respectively. The corresponding sRGO spectrum after exposing to sunlight for a period of $16 \mathrm{~h}$ is also shown in Fig. 1A (blue trace). Upon exposure to sunlight, the peak corresponding to $\pi-\pi^{*}$ transition of $\mathrm{C}-\mathrm{C}$ bonds is red shifted to $263 \mathrm{~nm}$ and the shoulder peak at $302 \mathrm{~nm}$ is completely disappeared, which indicates the restoration of $\mathrm{sp}^{2}$ carbon structure. UV/Vis spectra in Fig. 1B shows the reduction of GO to SRGO with respect to time. The shoulder peak at $302 \mathrm{~nm}$ is started diminishing in less than $8 \mathrm{~h}$ of exposure to sunlight and completely vanished after $16 \mathrm{~h}$. ATR-IR spectrum in Fig. 1C shows a broad band of $3200-3400 \mathrm{~cm}^{-1}$, which is due to $\mathrm{O}-\mathrm{H}$ stretching vibrations. GO shows peak centred at $1026 \mathrm{~cm}^{-1}$ (epoxy or alkoxy C-O), 1251 $\mathrm{cm}^{-1}$ (epoxy C-O), $1419 \mathrm{~cm}^{-1}$ (carboxyl C-O), $1650 \mathrm{~cm}^{-1}$ (aromatic $\mathrm{C}=\mathrm{C}), 1744 \mathrm{~cm}^{-1}(\mathrm{C}=\mathrm{O}$ of carboxylic acid). Upon exposure of GO to sunlight, most of the peaks correspond to oxygen functionalities are disappeared. Even the peaks intensity 

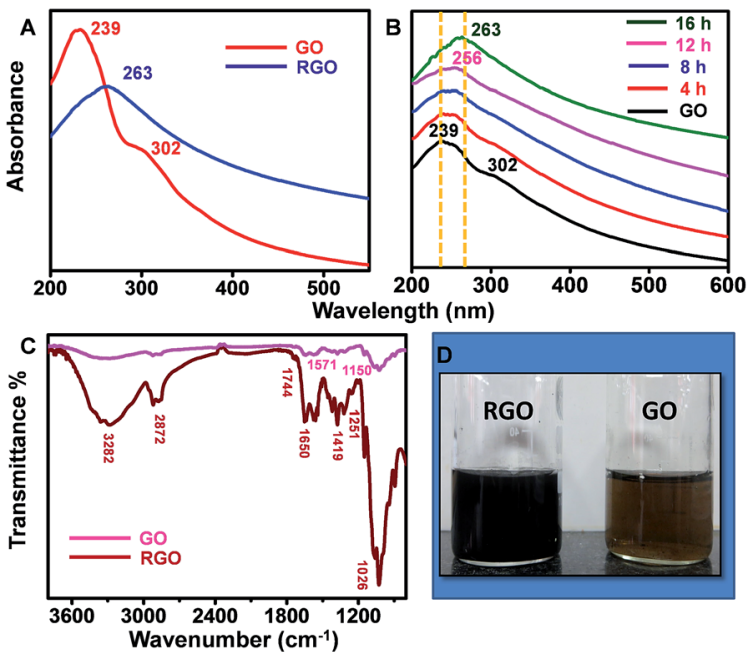

Fig. 1 (A) UV/Vis spectrum of GO and sRGO (B) the kinetics data showing the transformation of $\mathrm{GO}$ to sRGO with respect to time (C) ATR-IR spectrum of GO and sRGO (D) photographic images of GO (right) and sRGO (left). Traces are shifted vertically for clarity.

of carboxyl group at $1419 \mathrm{~cm}^{-1}$ is reduced significantly after $16 \mathrm{~h}$ of exposure. The reduced sample shows two prominent peaks centred at $1571 \mathrm{~cm}^{-1}$ and $1150 \mathrm{~cm}^{-1}$ and are due to the aromatic $\mathrm{C}=\mathrm{C}$ and $\mathrm{C}-\mathrm{O}$ stretching, respectively. ${ }^{29}$

Raman spectroscopy was employed to study the structural changes in graphene. ${ }^{30}$ It also helps in correlating the electrical conductivity with the structural defects. ${ }^{31}$ The features like local defects and disorders at the edges are reflected in two peaks namely D band $\left(\sim 1350 \mathrm{~cm}^{-1}\right)$ and $\mathrm{G}$ band $\left(\sim 1580 \mathrm{~cm}^{-1}\right)$ of the Raman spectra. The $\mathrm{D}$ band is due to the breathing modes of $\mathrm{sp}^{2}$ atoms in the aromatic rings and the $\mathrm{G}$ band corresponds to the single phonon process at the Brillouin point. In $\mathrm{GO}, \pi$ bonds are replaced by $\sigma$ carbon-oxygen/carbon-carbon bonds and the carbon atom hybridization change from $\mathrm{sp}^{2}$ to $\mathrm{sp}^{3}$, resulting in structural defects such as displacement of $\mathrm{C}$ atoms. The disappearance of the $\pi$ electrons increases the band gap. The Raman spectrum in Fig. 2A shows the D and G bands of GO at $1345 \mathrm{~cm}^{-1}$ and $1601 \mathrm{~cm}^{-1}$, respectively. After reduction, the $\mathrm{D}$ band position is intact, but the $\mathrm{G}$ band is shifted to 1591 $\mathrm{cm}^{-1}$. The shift in the $\mathrm{G}$ band is attributed to the increase in carrier concentration and mobility after reduction. ${ }^{32}$ The peak located at $\sim 2683 \mathrm{~cm}^{-1}$ represents $2 \mathrm{D}$ band, which originates from a two phonon inter-valley double resonance mechanism. The $\mathrm{D}+\mathrm{D}^{\prime}$ peak at $2923 \mathrm{~cm}^{-1}$ is due to the intra-valley scattering due to lattice defects. The shift in $\mathrm{G}$ band to a lower energy and a prominent increase in its $2 \mathrm{D}$ band confirm that GO sheets are converted to graphitic structures. The Fig. 2B compares Raman spectra of sRGO with hRGO and hyRGO. The enlarged $2 \mathrm{D}$ region of Raman spectra is shown in Fig. 2C. The figure clearly shows that there is a significant up-shift in the $2 \mathrm{D}$ band. The shift is more prominent in case of sRGO followed by hRGO. The up-shift variation of the $2 \mathrm{D}$ peak is due to the charge transfer with hole doping. ${ }^{33}$ For the systematic comparison of the charge transfer properties of RGO samples, $I_{\mathrm{D}} / I_{\mathrm{G}}$ and $I_{2 \mathrm{D}} / I_{\mathrm{G}}$ ratio are measured and correlated. It is established that $I_{\mathrm{D}} / I_{\mathrm{G}}$ ratio gives

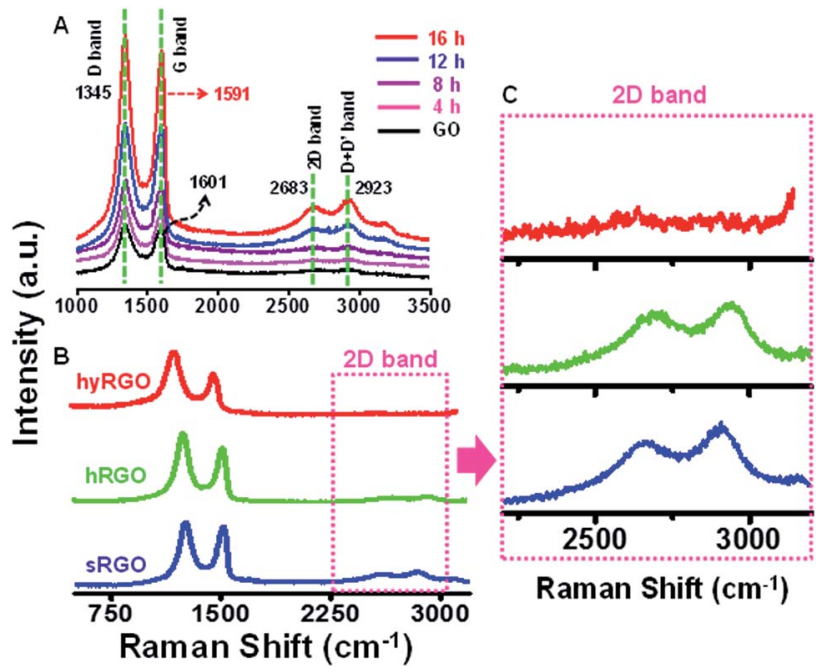

Fig. 2 Raman spectra showing (A) the reduction of GO to sRGO with respect to time, $(B)$ the comparison of Raman spectra of RGO samples synthesised by different reduction methods and (C) the enlarged 2D regions of various $\mathrm{RGO}$ samples.

the degree of defects present in RGO samples and $I_{2 \mathrm{D}} / I_{\mathrm{G}}$ ratio indicates the recovery of $\mathrm{sp}^{2} \mathrm{C}=\mathrm{C}$ bond in graphitic structure and hole mobility. ${ }^{34}$ Lower value of $I_{\mathrm{D}} / I_{\mathrm{G}}$ ratio indicates lesser defects and higher value of $I_{2 \mathrm{D}} / I_{\mathrm{G}}$ ratio indicates higher charge mobility. ${ }^{35}$ Table 1 summarises the $I_{\mathrm{D}} / I_{\mathrm{G}}$ and $I_{2 \mathrm{D}} / I_{\mathrm{G}}$ values obtained for various RGO samples. On comparison of $I_{2 \mathrm{D}} / I_{\mathrm{G}}$ ratio, it is clear that sRGO has the highest conductivity and least structural defects followed by hRGO and hyRGO.

For further confirming the charge mobility behaviour, the electrical conductivities of various RGO samples were measured using four-probe method [for detailed calculations see S2 of ESI $\dagger$. The four-probes were placed collinearly and interelectrode spacing of $2.5 \mathrm{~mm}$ was maintained. The current was passed through the two outer probes and the potential was measured between the two inner probes. The error due to electrical contacts are absent because the current and voltage leads are separate. The last column of Table 1 shows the electrical conductivities of various RGO samples. We can see that the conductivity data is consistent with Raman data.

Fig. 3 shows XPS spectra of carbon and oxygen content before and after photo-reduction. XPS peaks were fitted to Voigt functions having $80 \%$ Gaussian and $20 \%$ Lorentzian character, after performing Shirley background subtraction. ${ }^{36}$ The binding energy of $\mathrm{C} \mathrm{sp}^{2}$ group of graphene lies at $284.5 \mathrm{eV}$ or $284.6 \mathrm{eV}$.

Table 1 The $I_{\mathrm{D}} / /_{\mathrm{G}}$ and $/{ }_{2 \mathrm{D}} / /_{\mathrm{G}}$ ratios from Raman spectra and electrical conductivity values calculated by four-probe method for various RGO samples

\begin{tabular}{lccc}
\hline Samples & $I_{\mathrm{D}} / I_{\mathrm{G}}$ & $I_{2 \mathrm{D}} / I_{\mathrm{G}}$ & $\begin{array}{l}\text { Electrical conductivity } \\
\left(\text { in S m }^{-1}\right)\end{array}$ \\
\hline SRGO & 1.016 & 0.136 & 166.34 \\
hRGO & 1.194 & 0.069 & 133.06 \\
hyRGO & 1.550 & 0.010 & 68.56
\end{tabular}




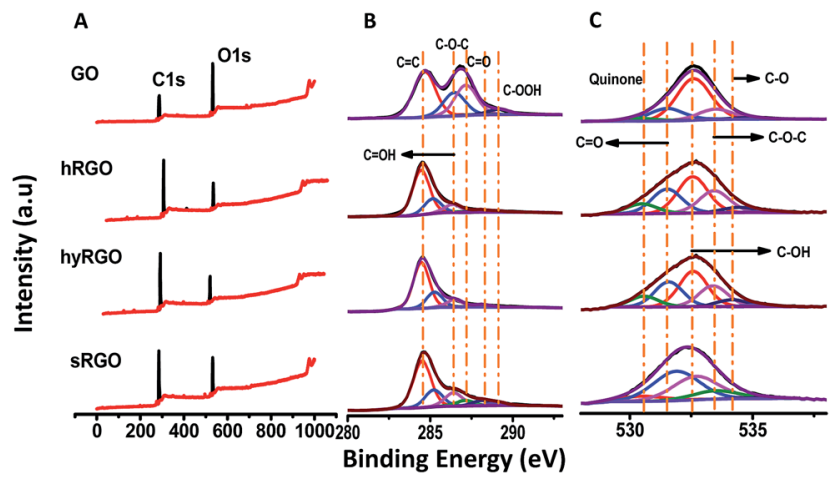

Fig. 3 (A) XPS survey spectra of GO, hRGO, hyRGO and sRGO with their respective $(B)$ deconvoluted $C 1$ s and $(C)$ deconvoluted $O 1$ s plots.

The other carbon-oxygen groups are shifted with respect to $\mathrm{C} \mathrm{sp}^{2}$. The peak positions at $286.4 \mathrm{eV}$ and $287.1 \mathrm{eV}$ corresponds to hydroxyl $(\mathrm{C}-\mathrm{OH})$ and epoxy $(\mathrm{C}-\mathrm{O}-\mathrm{C})$ groups, respectively. The smaller components at $288.1 \mathrm{eV}$ and $289.2 \mathrm{eV}$ are due to carbonyl $(\mathrm{C}=\mathrm{O})$ and carboxyl $(\mathrm{COOH})$ groups, respectively. ${ }^{37}$ From the relative intensity of the peaks, it is clear that oxygen groups present in GO are mainly due to epoxy, aldehyde and ketone groups located in the basal plane of GO sheets.

Upon reduction, there is a notable decrease in the intensity of the components associated to these basal plane groups. The deconvoluted C 1s spectra of various RGO samples (hRGO, hyRGO and SRGO) show maximum intense peak at $284.5 \mathrm{eV}$ that confirms the restoration of $\mathrm{C}-\mathrm{C}$ bonds after the reduction. The intensity of peaks at $286.4 \mathrm{eV}, 287.2 \mathrm{eV}$ and $288.1 \mathrm{eV}$ corresponding to hydroxyl, epoxy and carbonyl groups, respectively decreases after the reduction. The peak at $289.1 \mathrm{eV}$, which is due to the carboxylic group, remains after reduction. These residual peaks can be seen in hRGO and sRGO, but diminishes completely in the case of hyRGO. The data is also consistent with stability of different RGO dispersions prepared through various reduction routes. The stability of the samples in water follows the increasing order of sRGO $\approx \mathrm{hRGO}>$ hyRGO. This is evident from the zeta potential values (Table 1 of ESI $3 \uparrow$ ). The lower stability (low zeta potential value) of hyRGO can be due to complete reduction of carboxylic groups. It is reported that carboxylic acid groups are difficult to reduce by chemical or photochemical route. But, heating at $100-150{ }^{\circ} \mathrm{C}$ in hydrothermal condition can reduce the group significantly. ${ }^{38}$

The $\mathrm{O}$ 1s spectra were de-convoluted into six components that are assigned to quinone $(530.5 \mathrm{eV}), \mathrm{C}-\mathrm{OH}(531.9 \mathrm{eV})$, $\mathrm{C}-\mathrm{O}-\mathrm{C}(532.7 \mathrm{eV}), \mathrm{C}=\mathrm{O}(533.5 \mathrm{eV}), \mathrm{C}-\mathrm{O}(534.3 \mathrm{eV})$ and water $(535 \mathrm{eV}){ }^{39}$ The reduction in oxygen functionalities varies with different reduction methods.

The relative atomic contents (in \%) of carbon and oxygen components were calculated from the analysis of area under $\mathrm{C} 1 \mathrm{~s}, \mathrm{O} 1 \mathrm{~s}$ survey spectra. The values are summarised in Table 3. The relative sensitivity factors of carbon and oxygen were obtained from CASA XPS standard table. ${ }^{40}$ The calculated $\mathrm{C} / \mathrm{O}$ ratio of GO and RGO samples are summarised in Table 2.

Tables 3 and 4 show the fitted results of carbon (C 1s) and oxygen (O 1s) XPS spectra of RGO samples, respectively. The
Table 2 Elemental composition of GO and RGO determined by XPS survey spectra

\begin{tabular}{llll}
\hline Samples & $\mathrm{C}(\%)$ & $\mathrm{O}(\%)$ & $\mathrm{C} / \mathrm{O}$ \\
\hline GO & 67.87 & 32.13 & 2.11 \\
hRGO & 81.50 & 16.72 & 4.87 \\
hyRGO & 81.81 & 18.19 & 4.49 \\
sRGO & 78 & 22 & 3.54 \\
\hline
\end{tabular}

values represent the absolute amount of carbon and oxygen content before and after reduction. ${ }^{41}$ Table 3 shows that $\mathrm{C} \mathrm{sp}^{2}$ component increases after reduction, indicating the restoration of the graphitic structure. Meanwhile, majority of $\mathrm{C}-\mathrm{O}, \mathrm{C}-\mathrm{OH}$ groups are reduced considerably after reduction.

The fitted results of $O 1$ S XPS spectra in Table 4 shows that the $\mathrm{C}=\mathrm{O}$ peak decreases upon reduction whereas an increase in the quinone and $\mathrm{C}-\mathrm{O}$ peak is observed. This may be due to the transformation of the unstable oxygen groups to stable components during reduction process. ${ }^{41}$

Attempts were also done to assess the thermal conductivities of RGO samples. Equal concentrations of RGO samples (0.001 wt\%) were dispersed in distilled water and were subjected to thermal conductivity measurements by Prok2D probe at room temperature $\left(30 \pm 0.5{ }^{\circ} \mathrm{C}\right)$. The results are compared against distilled water to check the possible enhancement in the thermal conductivity. It is observed that all the samples tested showed comparable enhancement in the conductivity.

The data is summarised in Table 5. The dimensions of the graphene flakes including shape, size and the stability of nanofluids plays a major role in describing the physics behind the heat conduction. Sen Gupta et al., ${ }^{42}$ observed that, at lower concentrations of graphene dispersion, Brownian motion plays dominant role in deciding the thermal conductivity of the nanofluids. However, at higher concentrations, percolation starts dominating. In the present experiments, the shape and size of RGO sheets are comparable as we have used same GO as

Table 3 Atomic content of carbon fitted from XPS C 1s spectra of GO and RGO samples

\begin{tabular}{lllllll}
\hline B.E (eV) & 284.5 & 285.2 & 286.4 & 287.1 & 288.1 & 289.1 \\
Assignment & $\mathrm{C} \mathrm{sp}^{2}$ & $\mathrm{C} \mathrm{sp}^{3}$ & $\mathrm{C}-\mathrm{OH}$ & $\mathrm{C}-\mathrm{O}-\mathrm{C}$ & $\mathrm{C}=\mathrm{O}$ & $\mathrm{C}-\mathrm{OOH}$ \\
GO & 29.57 & - & 15.12 & 19.34 & 0.45 & 3.34 \\
hRGO & 50.63 & 16.65 & 9.26 & 0.96 & 2.77 & 1.16 \\
hyRGO & 51.92 & 17.61 & 8.52 & 0.84 & 2.90 & - \\
sRGO & 40.03 & 14.52 & 11.58 & 4.70 & 4.44 & 2.71
\end{tabular}

Table 4 Atomic content of oxygen fitted from XPS O 1s spectra of GO and RGO samples

\begin{tabular}{lllllll}
\hline B.E $(\mathrm{eV})$ & 530.5 & 531.9 & 532.7 & 533.5 & 534.3 & 535 \\
Assignment & Quinone & $\mathrm{C}-\mathrm{OH}$ & $\mathrm{C}-\mathrm{O}-\mathrm{C}$ & $\mathrm{C}=\mathrm{O}$ & $\mathrm{C}-\mathrm{O}$ & $\mathrm{H}_{2} \mathrm{O}$ \\
GO & 1.24 & 5.46 & 19.44 & 4.54 & 0.65 & - \\
hRGO & 1.68 & 4.16 & 6.21 & 3.77 & 0.92 & 0.27 \\
hyRGO & 1.94 & 4.50 & 6.37 & 3.76 & 1.26 & 0.34 \\
sRGO & 1.71 & 9.54 & 7.63 & 2.74 & - & 0.35
\end{tabular}


Table 5 Thermal conductivity and its comparative enhancement among RGO derived through different methods of reduction

\begin{tabular}{lll}
\hline Samples & $\begin{array}{l}\text { Thermal conductivity } \\
\left(\mathrm{W} \mathrm{m} \mathrm{K} \mathrm{m} \mathrm{K}^{-1}\right.\end{array}$ & $\begin{array}{l}\text { Enhancement } \\
(\%)\end{array}$ \\
\hline DI water & 0.670 & - \\
hRGO & 0.710 & 5.9 \\
SRGO & 0.709 & 5.8 \\
hyRGO & 0.706 & 5.4 \\
\hline
\end{tabular}

the starting material irrespective the reduction methods. However, the presence of functional group can vary with respect to the reducing agents used. At low concentration, the dispersibility of hRGO and sRGO are comparable and thus showed more or less similar results. The presence of less functional group in hyRGO and associated reduction in dispersibility may be the reason for the observed small reduction in the thermal conductivity of hyRGO compared to its counterparts. But one may expect a different behaviour in thermal conductivity at higher concentrations as the dominant mechanism involved is percolation and not the Brownian motion. It is worth to note that different reduction strategies result in different amounts and types of functional groups and hence likely change in thermal conductivity. But more investigations are required to establish the differences.

Fig. $4 \mathrm{~A}$ and $\mathrm{B}$ represent HRTEM images of RGO showing a sheet like morphology at different magnifications. The folding and the wrinkles that characterize the presence of $2 \mathrm{D}$ graphene sheets $^{43}$ are marked with white arrows in the Fig. 4A. The HRTEM data in Fig. 4B shows the grain boundary of RGO sheet marked as [1] represents 2 layered sheet and [2] represents 10 layered sheets. Fig. 4C shows AFM topological image and the corresponding height profile of the image is shown in Fig. 4D, which is taken on the horizontal blue line shown in the figure. The height image reveals the presence of 2-4 layers of RGO corresponding to $0.7-1.4 \mathrm{~nm}$ height. There are regions that show height profile of a few layers of RGO sheets one above another. This may be due to stacking of layers during the drying process of the specimen used for the analysis. This is also in consistent with HRTEM data.

\section{Proposed photo-reduction mechanism of GO to RGO}

The synthesis of GO involves oxygenation of graphite with the loss of $\pi$ electrons of the carbon atoms. This covalent functionalization converts $\mathrm{sp}^{2}$ to $\mathrm{sp}^{3}$ configuration. GO consist of both highly conducting $\mathrm{sp}^{2}$ regions and insulating or semiconducting $\mathrm{sp}^{3}$ regions. The disappearance of $\pi$ electrons opens the bandgap which can be tuned in proportion with the oxygen functional groups. Normally, during photo-reduction, the bandgap excitation of the semiconducting region is responsible for reduction process and not the thermal effect. ${ }^{44}$ Also, the absorbance of light depends on the bandgap. In the present study, the photo-reduction of GO with bandgap energy

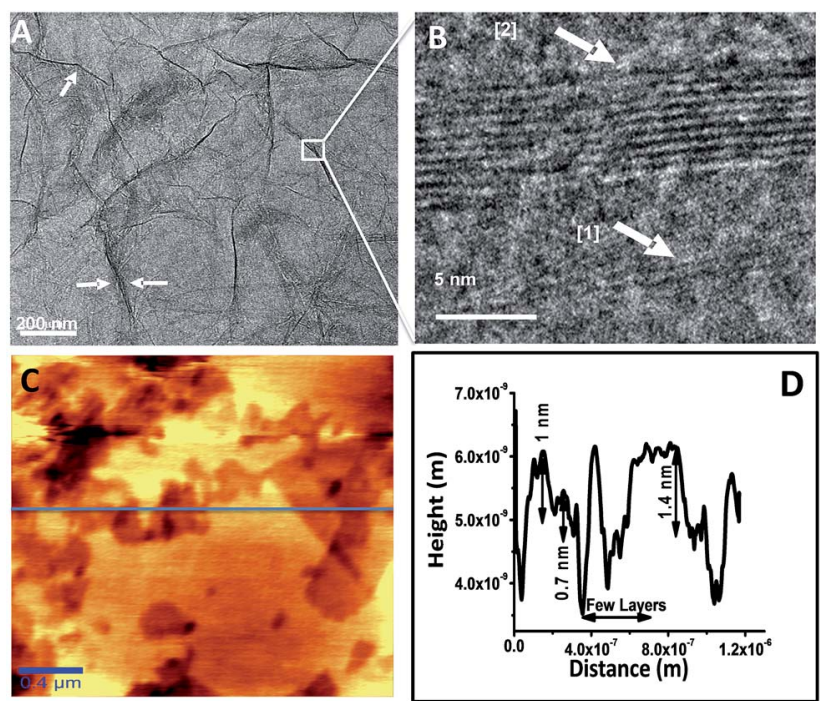

Fig. 4 (A) HRTEM image of sRGO sheets (white arrows marked in the figure represents the wrinkles) (B) the grain boundary of RGO sheets of 2 and 10 layers magnified at the specified location (C) AFM image of sRGO and (D) height profile of sRGO sheets (along the blue line in (C)).

of $3.09 \mathrm{eV}$ [see S4 of ESI $\dagger$ for details] is carried out by exposing the aqueous dispersion of $0.01 \% \mathrm{GO}(\mathrm{pH} \sim 4)$ to sunlight. The liberation of $\mathrm{H}^{+}$and $\mathrm{OH}^{-}$ions and solvated electrons during photodecomposition of water molecules can enhances the reduction process. The possible reduction mechanism of GO to RGO is explained.

On exposure of GO to sunlight, it absorbs photons of energy equal to or larger than its bandgap in-order to generate electrons in the conduction band and holes in the valence band. These electrons and holes contribute to the redox reactions on GO sheet. The single bonded hydroxyl and epoxy groups attached to the basal plane are considered as highly reactive groups and hence the reduction of such groups happens readily.

The disappearances of these groups at early hours of the exposure to sunlight are evident from the Fig. 1B. A complete removal of these groups was observed within $8 \mathrm{~h}$ of exposure to sunlight. The possible pathways of reduction of these groups are described by the chemical reactions (R1) and (R2). Visible formation of gas bubbles in the reactor during the first $3 \mathrm{~h}$ of exposure to sunlight also supports a similar reduction route. The presence of functional groups in graphene and the liberation of $\mathrm{CO}_{2}$ during the reduction of $\mathrm{GO}$ are expected to increase the defects and in turn reduce the conductivity of graphene. ${ }^{45}$ The release of $\mathrm{CO}_{2}$ is also confirmed by decrease in total carbon content [see S5 of ESI $\dagger$ for details] with an increase in the inorganic carbon. ${ }^{46}$ However, the experimental evidences have shown a reverse behaviour. Interestingly, sRGO has showed enhanced conductivity compared to RGO samples prepared through other routes. This enhancement in conductivity can be due to the liberation of $\mathrm{H}_{2}$ at the defect region as given in the eqn (R3).

$$
\mathrm{GO}\left(\mathrm{sp}^{3} \text { region }\right)+h \gamma \rightarrow \mathrm{e}^{-}+\mathrm{h}^{+}
$$




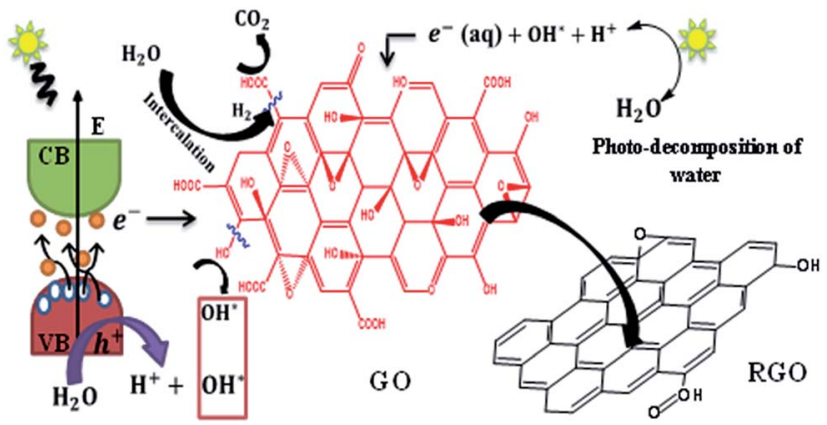

Fig. 5 Schematic showing the formation of sRGO from GO.

$$
\begin{array}{r}
2 \mathrm{C}-\mathrm{OH}+\mathrm{H}_{2} \mathrm{O}+3 \mathrm{~h}^{+}+\mathrm{e}^{-} \rightarrow \mathrm{C} \text { (defects) }+\mathrm{CO}_{2}+\mathrm{H}_{2} \mathrm{O} \\
2 \mathrm{C}-\mathrm{O}-\mathrm{C}+\mathrm{H}_{2} \mathrm{O}+2 \mathrm{~h}^{+}+2 \mathrm{e}^{-} \rightarrow \\
\mathrm{C} \text { (defects) }+\mathrm{C}-\mathrm{C} \text { (defects) }+\mathrm{CO}_{2}+\mathrm{H}_{2} \mathrm{O} \\
2 \mathrm{H}_{2} \mathrm{O}+\mathrm{C}(\text { defect })+2 \mathrm{e}^{-}+2 \mathrm{~h}^{+} \rightarrow \mathrm{H}_{2}+\mathrm{CO}_{2}+\mathrm{H}_{2} \mathrm{O}
\end{array}
$$

It is to be noted that there is a tendency for the electropositive carbon defect to attract the highly electronegative oxygen atom of the water molecules (Fig. 5). This process can enable the liberation of $\mathrm{H}_{2}$ at the defect sites and re-establish the conjugated $\pi$ networks and provide higher conductivity. As the irradiation duration is increased, the production of $\mathrm{H}_{2}$ also increased. ${ }^{47}$

The possible enhanced release of $\mathrm{H}_{2}$ and corresponding reestablishment of the conjugated $\pi$ networks can be the reason for the observed higher conductivity. The higher electrical conductivity of hRGO compared to other RGO samples is due to the nitrogen incorporation from the reducing agent (hydrazine monohydrate). The formation of hydrazones results in the removal of oxygen functional groups in hRGO. ${ }^{48}$

\section{Conclusion}

The reduction of GO by sunlight can be employed as an energy saving alternative for the large-scale preparation of RGO. The method is simple and sustainable compared to the conventional methods of reduction of GO. sRGO synthesized by this method exhibited higher electrical conductivity, least structural defects and good dispersibility compared to other RGO samples tested. The data shows that the proposed reduction route is feasible and a sustainable option to produce dispersible RGO with good electrical conductivity. The study also caution using GO in any device components which may undergo prolonged exposure to sunlight.

\section{Acknowledgements}

Authors gratefully acknowledge the Department of Science and Technology (DST), Government of India, Research and development grant under water technology initiative (DST/WTI/2K14/228) for partially supporting the work. The authors also thank VIT
University for supporting the work. Thanks are due to Mr Sudhakar, DST unit on Nanoscience and Technology, IIT Madras for helping in XPS analysis.

\section{References}

1 J. C. Meyer, A. K. Geim, M. Katsnelson, K. Novoselov, T. Booth and S. Roth, Nature, 2007, 446, 60-63.

2 M. J. Allen, V. C. Tung and R. B. Kaner, Chem. Rev., 2010, 110, 132-145.

3 Y. Zhu, S. Murali, W. Cai, X. Li, J. W. Suk, J. R. Potts and R. S. Ruoff, Adv. Mater., 2010, 22, 3906-3924.

4 K. S. Novoselov, A. K. Geim, S. V. Morozov, D. Jiang, Y. Zhang, S. V. Dubonos, I. V. Grigorieva and A. A. Firsov, Science, 2004, 306, 666-669.

5 D. Sen, K. S. Novoselov, P. M. Reis and M. J. Buehler, Small, 2010, 6, 1108-1116.

6 J. Robinson, X. Weng, K. Trumbull, R. Cavalero, M. Wetherington, E. Frantz, M. LaBella, Z. Hughes, M. Fanton and D. Snyder, ACS Nano, 2009, 4, 153-158.

7 D. Arco, L. Gomez, Y. Zhang, A. Kumar and C. Zhou, IEEE Trans. Nanotechnol., 2009, 8, 135-138.

8 A. Reina, X. Jia, J. Ho, D. Nezich, H. Son, V. Bulovic, M. S. Dresselhaus and J. Kong, Nano Lett., 2009, 9, 3087.

9 J. K. Wassei and R. B. Kaner, Mater. Today, 2010, 13, 52-59. 10 G. Eda and M. Chhowalla, Adv. Mater., 2010, 22, 2392-2415. 11 S. Park and R. S. Ruoff, Nat. Nanotechnol., 2009, 4, 217-224. 12 K.-H. Liao, A. Mittal, S. Bose, C. Leighton, K. A. Mkhoyan and C. W. Macosko, ACS Nano, 2011, 5, 1253-1258.

13 T. Sreeprasad, S. M. Maliyekkal, K. Lisha and T. Pradeep, J. Hazard. Mater., 2011, 186, 921-931.

14 S. H. Anderson and D. D. L. Chung, Carbon, 1984, 22, 253-263. 15 C. Botas, P. Álvarez, C. Blanco, R. Santamaría, M. Granda, M. D. Gutiérrez, F. Rodríguez-Reinoso and R. Menéndez, Carbon, 2013, 52, 476-485.

16 H. C. Schniepp, J.-L. Li, M. J. McAllister, H. Sai, M. HerreraAlonso, D. H. Adamson, R. K. Prud'homme, R. Car, D. A. Saville and I. A. Aksay, J. Phys. Chem. B, 2006, 110, 8535-8539.

17 M. J. Fernández-Merino, J. I. Paredes, S. Villar-Rodil, L. Guardia, P. Solís-Fernández, D. Salinas-Torres, D. Cazorla-Amorós, E. Morallón, A. Martínez-Alonso and J. M. D. Tascón, Carbon, 2012, 50, 3184-3194.

18 W. S. Hummers and R. E. Offeman, J. Am. Chem. Soc., 1958, 80, 1339.

19 S. Pei and H.-M. Cheng, Carbon, 2012, 50, 3210-3228.

20 X. Mei, X. Meng and F. Wu, Phys. E, 2015, 68, 81-86.

21 D. Zhan, Z. Ni, W. Chen, L. Sun, Z. Luo, L. Lai, T. Yu, A. T. S. Wee and Z. Shen, Carbon, 2011, 49, 1362-1366.

22 Y. Matsumoto, M. Koinuma, S. Y. Kim, Y. Watanabe, T. Taniguchi, K. Hatakeyama, H. Tateishi and S. Ida, ACS Appl. Mater. Interfaces, 2010, 2, 3461-3466.

23 P. Kumar, K. Subrahmanyam and C. Rao, Int. J. Nanosci., 2011, 10, 559-566.

24 H. Wang, J. T. Robinson, X. Li and H. Dai, J. Am. Chem. Soc., 2009, 131, 9910-9911. 
25 S. Park, J. An, J. R. Potts, A. Velamakanni, S. Murali and R. S. Ruoff, Carbon, 2011, 49, 3019-3023.

26 D. R. Dreyer, S. Park, C. W. Bielawski and R. S. Ruoff, Chem. Soc. Rev., 2010, 39, 228-240.

27 S. Jin, Q. Gao, X. Zeng, R. Zhang, K. Liu, X. Shao and M. Jin, Diamond Relat. Mater., 2015, 58, 54-61.

28 D. C. Marcano, D. V. Kosynkin, J. M. Berlin, A. Sinitskii, Z. Sun, A. Slesarev, L. B. Alemany, W. Lu and J. M. Tour, ACS Nano, 2010, 4, 4806-4814.

29 D. Konios, M. M. Stylianakis, E. Stratakis and E. Kymakis, J. Colloid Interface Sci., 2014, 430, 108-112.

30 A. C. Ferrari and J. Robertson, Phys. Rev. B: Condens. Matter Mater. Phys., 2000, 61, 14095-14107.

31 A. C. Ferrari, J. C. Meyer, V. Scardaci, C. Casiraghi, M. Lazzeri, F. Mauri, S. Piscanec, D. Jiang, K. S. Novoselov, S. Roth and A. K. Geim, Phys. Rev. Lett., 2006, 97, 187401.

32 D. M. Basko, S. Piscanec and A. C. Ferrari, Phys. Rev. B: Condens. Matter Mater. Phys., 2009, 80, 165413.

33 S. Eigler, F. Hof, M. Enzelberger-Heim, S. Grimm, P. Müller and A. Hirsch, J. Phys. Chem. C, 2014, 118, 7698-7704.

34 Y. Su, J. Du, D. Sun, C. Liu and H. Cheng, Nano Res., 2013, 6, 842-852.

35 C.-Y. Su, Y. Xu, W. Zhang, J. Zhao, X. Tang, C.-H. Tsai and L.-J. Li, Chem. Mater., 2009, 21, 5674-5680.

36 D. Yang, A. Velamakanni, G. Bozoklu, S. Park, M. Stoller, R. D. Piner, S. Stankovich, I. Jung, D. A. Field and C. A. Ventrice, Carbon, 2009, 47, 145-152.

37 L. Stobinski, B. Lesiak, A. Malolepszy, M. Mazurkiewicz, B. Mierzwa, J. Zemek, P. Jiricek and I. Bieloshapka, J. Electron Spectrosc. Relat. Phenom., 2014, 195, 145-154.
38 Y. Zhou, Q. Bao, L. A. L. Tang, Y. Zhong and K. P. Loh, Chem. Mater., 2009, 21, 2950-2956.

39 S. Rella, A. Giuri, C. E. Corcione, M. R. Acocella, S. Colella, G. Guerra, A. Listorti, A. Rizzo and C. Malitesta, Vacuum, 2015, 119, 159-162.

40 V. Štengl, S. Bakardjieva, T. M. Grygar, J. Bludská and M. Kormunda, Chem. Cent. J., 2013, 7, 1-12.

41 C.-M. Chen, Q. Zhang, M.-G. Yang, C.-H. Huang, Y.-G. Yang and M.-Z. Wang, Carbon, 2012, 50, 3572-3584.

42 S. Sen Gupta, V. Manoj Siva, S. Krishnan, T. S. Sreeprasad, P. K. Singh, T. Pradeep and S. K. Das, J. Appl. Phys., 2011, 110, 084302.

43 S. M. Maliyekkal, T. Sreeprasad, D. Krishnan, S. Kouser, A. K. Mishra, U. V. Waghmare and T. Pradeep, Small, 2013, 9, 273-283.

44 B. Konkena and S. Vasudevan, J. Phys. Chem. C, 2015, 119, 6356-6362.

45 M. Agharkar, S. Kochrekar, S. Hidouri and M. A. Azeez, Mater. Res. Bull., 2014, 59, 323-328.

46 W.-C. Hou, I. Chowdhury, D. G. Goodwin Jr, W. M. Henderson, D. H. Fairbrother, D. Bouchard and R. G. Zepp, Environ. Sci. Technol., 2015, 49, 3435-3443.

47 Y. Matsumoto, M. Koinuma, S. Ida, S. Hayami, T. Taniguchi, K. Hatakeyama, H. Tateishi, Y. Watanabe and S. Amano, J. Phys. Chem. C, 2011, 115, 19280-19286.

48 P. Zhu, M. Shen, S. Xiao and D. Zhang, Phys. B, 2011, 406, 498-502. 